\title{
Identification of Fungal Pathogens in Otomycosis and Their Drug Sensitivity: Our Experience
}

\author{
Khaled Ali ${ }^{1}$ Mahmood A. Hamed ${ }^{1}$ Hameda Hassan ${ }^{2}$ Amira Esmail ${ }^{2}$ Abeer Sheneef ${ }^{2}$
} 1 Department of Otorhinolaryngology, Sohag University Faculty of
Medicine, Sohag, Egypt
2Department of Medical Microbiology and Immunology,
Sohag University Faculty of Medicine, Sohag, Egypt
Address for correspondence Mahmood A. Hamed, MD, Department of Otorhinolaryngology, Sohag University Faculty of Medicine, East District, Sohag, 82525, Egypt

(e-mail: mahmoodhamed8@gmail.com).

Int Arch Otorhinolaryngol 2018;22:400-403.

\begin{abstract}
Keywords

- otomycosis

- yeast

- aspergillus

- antifungal agents

- candida

- dermatophytes

Introduction Otomycosis is a common problem in otolaryngology practice. However, we usually encounter some difficulties in its treatment because many patients show resistance to antifungal agents, and present high recurrence rate.

Objectives To determine the fungal pathogens that cause otomycosis as well as their susceptibility to the commonly used antifungal agents. Additionally, to discover the main reasons for antifungal resistance.

Methods We conducted an experimental descriptive study on 122 patients clinically diagnosed with otomycosis from April 2016 to April 2017. Aural discharge specimens were collected for direct microscopic examination and fungal culture. In vitro antifungal susceptibility testing was performed against the commonly used antifungal drugs. We tested the isolated fungi for their enzymatic activity.

Results Positive fungal infection was found in 102 samples. The most common fungal pathogens were Aspergillus and Candida species, with Aspergillus niger being the predominant isolate (51\%). The antifungal susceptibility testing showed that mold isolates had the highest sensitivity to voriconazole (93.48\%), while the highest resistance was to fluconazole (100\%). For yeast, the highest sensitivity was to nystatin (88.24\%), followed by amphotericin B $(82.35 \%)$, and the highest resistance was to terbinafine (100\%), followed by Itraconazole (94.12\%). Filamentous fungi expressed a high enzymatic ability, making them more virulent.

Conclusion The Aspergillus and Candida species are the most common fungal isolates in otomycosis. Voriconazole and Nystatin are the medications of choice for the treatment of otomycosis in our community. The high virulence of fungal pathogens is owed to their high enzymatic activity. Empirical use of antifungals should be discouraged.
\end{abstract}

\section{Introduction}

Otomycosis is a common condition, frequently encountered in otolaryngology outpatient clinics. It is defined as a fungal infection affecting the external ear canal in the majority of cases. Less commonly, it can involve the middle ear, if the drum is perforated, and the mastoid cavity following an open mas-

received

October 17, 2017

accepted

December 17, 2017

published online

April 12, 2018 
Penicillium, Fusarium, Mucoraceae, Scopulariopsis, Alternaria, Malassezia, and Candida, as well as various dermatophytes. $^{4-6}$ Common risk factors for otomycosis are poor hygienic conditions; minor trauma; inflammation or physical injury; use of swimming pools; being exposed to hot humid atmospheres, as in tropical and subtropical areas; prolonged use of antibiotics, and use of steroid ear drops in those with impaired immune system.,7-9

Many antifungal agents were prescribed for otomycosis eradication, including azole group antifungals, amphotericin $\mathrm{B}$, boric acid, mercurochrome (1\%-2\% solution) and phenylmercuric acetate $(0.02 \%)$ in sterile water, urea-acetic acid solution, or aluminum acetate solution (5\%). ${ }^{10-13}$ In the present study, we focused on the causative fungi for otomycosis in our region, as well as on their susceptibility to the commonly used antifungal agents. In addition, we tried to clarify the reason for newly emerged antifungal resistance.

\section{Methods}

This study fulfills the requirements of the regional and institutional ethical guidelines on studies involving human participants as well as those of the Helsinki declaration. An informed consent was obtained from all patients enrolled in this work.

Patients' selection: an experimental descriptive study was performed on patients clinically diagnosed with otomycosis who attended our otolaryngology outpatient clinic for 1 year (April 2016 to April 2017). Those patients presented with different complaints, including aural pain, itching, otorrhea, with or without hearing loss, and their examination revealed erythema, fungal debris and creamy or blackish aural discharge. Those who had recent history of antifungal topical medication were excluded from our study.

Specimen preparation $\mathcal{E}$ processing: After the clinical diagnosis was established, specimens from the external ear canal were collected from all patients by means of sterile cotton swabs under aseptic conditions. Each sample was divided into two parts for fungal analysis. One part was clarified with a $10 \%$ potassium hydroxide solution on a glass slide for direct microscopic examination. The second part of the specimen was mounted on the surface of two Sabouraud's dextrose agar (SDA) plates supplemented with $0.05 \mathrm{mg} / \mathrm{mL}$ of chloramphenicol (AppliChem GmbH, Darmstadt, Germany); one was incubated at $37^{\circ} \mathrm{C}$ and the other was incubated at $27^{\circ} \mathrm{C}$. Incubation of both plates continued for at least 4 weeks with daily examination for the first week, then twice weekly for the next 3 weeks until the colonies appeared or revealed no growth.

The growing fungi were kept for further mycological testing in SDA slants and sterile Eppendorf tubes containing sterile glycerol in distilled water with a concentration of $20 \%$ for yeasts, and a concentration of $10 \%$ for filamentous fungi. In addition, Vitek-2 (bioMérieux, Marcy-L'Etoile, France) was used for complete identification of Candida species. ${ }^{14}$

Antifungal susceptibility testing: the antifungal susceptibility testing was performed using the disc diffusion method. ${ }^{15}$ The antifungal agents tested were: polyenes; (amphotericin B 100 units and nystatin 100 units), azoles; (fluconazole $25 \mu \mathrm{g}$, ketoconazole $10 \mu \mathrm{g}$, clotrimazole $10 \mu \mathrm{g}$, voriconazole $1 \mu \mathrm{g}$ and itraconazole $10 \mu \mathrm{g}$ ) and terbinafine $25 \mu \mathrm{g}$. All the antifungal discs were obtained from HiMedia, India, except for terbinafine ( $25 \mu \mathrm{g})$ and itraconazole $(10 \mu \mathrm{g})$, which were locally prepared. The isolated yeast and filamentous fungi were tested for extracellular enzyme (urease, lipase and protease) production, according to previously described methods. ${ }^{16,17}$

Statistical analysis; Data were analyzed using the STATA intercooled version 12.1 (Stata Corp. LP, College Station, TX). Quantitative data were expressed as mean, standard deviation, median and range. Qualitative data were presented as numbers and percentages.

\section{Results}

Our study included 112 patients clinically diagnosed with otomycosis. Of these patients, 102 revealed fungal pathogens. Fifty-nine of the patients were male (57.84\%). Their ages ranged between 9 months and 71 years, with the highest proportion among the $21-30$ years age group, median 25.7 years (27\%).

The most common presenting symptom was pruritis, in 94 cases (92.16\%), followed by otalgia, in 52 cases (50.98\%), otorrhea, in 21cases (20.59\%), hearing loss, in 22 cases (23.53\%) and tinnitus, in 10 cases (9.8\%).

The causative agents for otomycosis in our study were described in - Table 1. Aspergillus niger was the most common fungus, having been found in 49 cases (48.04\%).

\section{Antifungal Susceptibility Testing (AST) of Isolated Filamentous Fungi}

Antifungal susceptibility testing of 92 mold isolates was performed using the disc diffusion method (-Table 2 ). The highest percentage of sensitivity among mold isolates was to voriconazole (93.48\%), followed by terbinafine (75\%). Surprisingly, all isolates were resistant to fluconazole.

\section{Antifungal Susceptibility Testing of Isolated Yeasts}

Antifungal susceptibility testing of 17 yeast isolates was performed using the disc diffusion method. For the used antifungal agents, the highest percentage of sensitivity among yeast isolates was to nystatin (88\%), followed by amphotericin $\mathrm{B}(82 \%)$. All yeast isolates were resistant to terbinafine (100\%) and resistance to itraconazole was observed in $94.12 \%$.

\section{Discussion}

Otomycosis is a common clinical entity. Although not life threatening, it can be a frustrating condition for both patient and physician due to the need for a long-term therapy, regular follow-up and tendency for recurrence. ${ }^{18}$

In this study, the most common symptoms of otomycosis were pruritis (92.16\%) and otalgia (50.98\%). Other common complaints were hearing loss (23.53\%) and ear discharge (20.59\%). The mentioned complaints and their incidence were in accordance with the findings of other studies. ${ }^{19,20}$ However, some reports stated that otalgia was the most 
402 Identification of Fungal Pathogens in Otomycosis and Their Drug Sensitivity Ali et al.

Table 1 Distribution of patients with otomycosis according to isolated fungal pathogens

\begin{tabular}{|l|l|}
\hline Microorganisms & Number (\%) \\
\hline Aspergillus niger & $49(48.04 \%)$ \\
\hline Aspergillus flavus & $31(30.39 \%)$ \\
\hline Candida famata & $3(2.94 \%)$ \\
\hline Aspergillus terreus & $2(1.96 \%)$ \\
\hline Candida parapsilosis & $2(1.96 \%)$ \\
\hline Candida utiliz & $2(1.96 \%)$ \\
\hline Rhizopus stolonifer & $2(1.96 \%)$ \\
\hline Candida guilliermondii & $1(0.98 \%)$ \\
\hline Candida krusei & $1(0.98 \%)$ \\
\hline Cryptococcus laurentii & $1(0.98 \%)$ \\
\hline Penicillium duclauxi & $1(0.98 \%)$ \\
\hline A. flavus + C. utiliz & $2(1.96 \%)$ \\
\hline A. flavus + C. famata & $1(0.98 \%)$ \\
\hline A. niger + C. guillerimondii & $1(0.98 \%)$ \\
\hline A. niger + C. krusei & $1(0.98 \%)$ \\
\hline A. niger + C. utiliz & $1(0.98 \%)$ \\
\hline A. terreus + Cryptococcus laurentii & $1(0.98 \%)$ \\
\hline Total & $102(100 \%)$ \\
\hline
\end{tabular}

frequent symptom. ${ }^{21}$ Accordingly, absence of pruritis does not exclude the possibility of otomycosis.

Previous reports have concluded that the diagnostic yield of direct microscopic examination (DME) may range from 10 to more than $90 \%$, depending on the fungal species. ${ }^{22}$ In this study, only 10 samples were positive for fungal infection on DME (8.2\%), while on SDA culture, the percentage of samples positive for fungal infection was $83.61 \%$ (102 of total collected samples). Therefore, culture is the main diagnostic tool. $^{22}$

In our study, A. niger (50.98\%) was the most common isolated organism, followed by Aspergillus flavus (33.33\%), and then by Candida species (14.7\%). This is in accordance with other studies. ${ }^{23,24}$ However, the predominant fungal pathogens in otomycosis were different in various literature reports, including $A$. flavus $^{18,25}$ Aspergillus fumigates ${ }^{26}$ and Candida. ${ }^{5,27}$ We owed this difference to the variability in geographic distribution and environmental factors.

This study revealed that voriconazole and nystatin should have the upper hand in treatment of otomycosis. Moreover, it was informative enough to explain one of the main reasons for lack of response to commonly prescribed antifungals and high recurrence rate, which was recently observed in our practice with prescription of fluconazole as a first-line treatment for our cases.

Another reason is the urease activity, which was proven to play a crucial role for fungal pathogens, particularly those that initiate infection via the lungs. ${ }^{28}$ Stehr et al confirmed that

Table 2 Antifungal susceptibility pattern of mold isolates against various antifungal agents

\begin{tabular}{|c|c|c|c|c|c|c|c|c|c|c|}
\hline \multirow[t]{2}{*}{ Name } & \multirow[t]{2}{*}{ No } & \multirow{2}{*}{$\begin{array}{l}\text { Drug } \\
\text { sensitivity }\end{array}$} & AP & NS & FU & IT & VOR & KT & CLO & TF \\
\hline & & & N (\%) & N (\%) & N (\%) & N (\%) & N (\%) & N (\%) & N (\%) & N (\%) \\
\hline \multirow[t]{3}{*}{ A. niger } & \multirow[t]{3}{*}{52} & $S$ & $48(92.3)$ & $29(55.77)$ & 0 & $29(55.77$ & $51(98.08)$ & 0 & 0 & $37(71.15)$ \\
\hline & & 1 & $2(3.85)$ & $22(42.31)$ & 0 & $12(23.08)$ & 0 & $23(44.23)$ & $36(69.23)$ & $11(21.15)$ \\
\hline & & $R$ & $2(3.85)$ & 1 (1.92) & $52(100)$ & $11(21.15)$ & $1(1.92)$ & $29(55.77)$ & $16(30.77)$ & 4 (7.69) \\
\hline \multirow[t]{3}{*}{ A. flavus } & \multirow[t]{3}{*}{34} & $\mathrm{~S}$ & $1(2.94)$ & $18(52.94)$ & 0 & $17(50)$ & $32(94.12)$ & $13(38.24)$ & $5(14.71)$ & $30(88.24)$ \\
\hline & & 1 & $2(5.88)$ & $13(38.24)$ & 0 & $7(20.59)$ & $2(5.88)$ & $21(61.76)$ & 29 (85.29) & $1(2.94)$ \\
\hline & & $R$ & 31 (91.18) & $3(8.82)$ & $34(100)$ & $10(29.41)$ & 0 & 0 & 0 & $3(8.82)$ \\
\hline \multirow[t]{3}{*}{ A. terreus } & \multirow[t]{3}{*}{3} & $S$ & 0 & 0 & 0 & 0 & $3(100)$ & 0 & $2(66.67)$ & $1(33.33)$ \\
\hline & & 1 & 0 & $3(100)$ & 0 & $2(66.67)$ & 0 & $3(100)$ & $1(33.33)$ & $2(66.67)$ \\
\hline & & $R$ & $3(100)$ & 0 & $3(100)$ & $1(33.33)$ & 0 & 0 & 0 & 0 \\
\hline \multirow{3}{*}{$\begin{array}{l}\text { Rhizopus } \\
\text { stolonifer }\end{array}$} & \multirow[t]{3}{*}{2} & $S$ & 0 & 0 & 0 & 0 & 0 & 0 & 0 & 0 \\
\hline & & 1 & $1(50)$ & $2(100)$ & 0 & 0 & 0 & 0 & 0 & 0 \\
\hline & & $R$ & $1(50)$ & 00 & $2(100)$ & $2(100)$ & $2(100)$ & $2(100)$ & $2(100)$ & $2(100)$ \\
\hline \multirow{3}{*}{$\begin{array}{l}\text { Penicillium } \\
\text { duclauxi }\end{array}$} & \multirow[t]{3}{*}{1} & $S$ & 0 & $1(100)$ & 0 & 0 & 0 & 0 & 0 & $1100)$ \\
\hline & & 1 & 0 & 0 & 0 & 0 & 0 & 0 & 0 & 0 \\
\hline & & $R$ & $1(100)$ & 0 & $1(100)$ & $1(100)$ & $1(100)$ & $1(100)$ & $1(100)$ & 0 \\
\hline \multirow[t]{3}{*}{ Total } & \multirow[t]{3}{*}{92} & $S$ & $49(53.26)$ & $48(52.17)$ & 0 & $46(50)$ & 86 (93.48) & $13(14.13)$ & $7(7.61)$ & $69(75.00)$ \\
\hline & & 1 & $5(5.43)$ & $40(43.48)$ & 0 & $21(22.83)$ & $2(2.17)$ & 47 (51.09) & $66(71.74)$ & $14(15.22)$ \\
\hline & & $R$ & $38(41.3)$ & $4(4.35)$ & $92(100)$ & $25(27.17)$ & $4(4.35)$ & $32(34.78)$ & $19(20.65)$ & $9(9.78)$ \\
\hline
\end{tabular}

Abbreviations: AP, amphotericin; CLO, clotrimazole; FU, fluconazole; I, intermediate; IT, itraconazole; KT, ketoconazole; NS, nystatin; R, resistant; S, sensitive; TF, terbinafine; VOR, voriconazole. 
Candida lack the urease enzyme, and urea is instead metabolized by a urea amidolyase. ${ }^{29}$ In our study, $93.39 \%$ of isolated filamentous fungi and Cryptococcus were urease-positive. All Candida isolates were urease-negative. In addition, Yike mentioned the fact that the external digestion of protein substrates by secreted proteases is an essential requirement for survival and growth of both saprophytic and pathogenic fungal species. ${ }^{30}$ In our study, $31.52 \%$ of mold isolates were high enzyme producers, $20.65 \%$ were intermediate enzyme producers, $46.74 \%$ were low enzyme producers and only $1.09 \%$ were non-enzyme producers. For isolated yeasts, $64.71 \%$ of isolates were low enzyme producers, $17.65 \%$ of isolates were intermediate enzyme producers and $17.65 \%$ of isolates were nonenzyme producers. These results might explain the high virulence and resistance of mold isolates to the commonly prescribed antifungals as well as the high rate of recurrence. Moreover, our results clarify how important the in vitro antifungal susceptibility testing is. Filamentous fungi possess a high enzymatic ability, which makes them more virulent, and the infections caused by these fungi are more aggressive. Our recommendation is to avoid the empirical prescription of antifungal drugs. If in vitro antifungal susceptibility testing cannot be routinely done, fluconazole should be discarded for treatment of otomycosis for these types of patients.

\section{Conclusion}

This study revealed that Aspergillus and Candida species were the most common fungal pathogens causing otomycosis. Aspergillus niger is the predominant fungal isolate.

Mold isolates showed highest sensitivity to Voriconazole, while the highest resistance was to Fluconazole. For yeast isolates, the highest sensitivity was to Nystatin, and the highest resistance was to terbinafine. Filamentous fungi possess a high enzymatic ability, which makes them more virulent, aggressive and resistant to treatment. Empirical use of antifungals in otomycosis should not be a routine practice.

\section{References}

1 Munguia R, Daniel SJ. Ototopical antifungals and otomycosis: a review. Int J Pediatr Otorhinolaryngol 2008;72(04):453-459

2 Pontes ZB, Silva AD, Lima EdeO, et al. Otomycosis: a retrospective study. Rev Bras Otorrinolaringol (Engl Ed) 2009;75(03):367-370

3 Kaur R, Mittal N, Kakkar M, Aggarwal AK, Mathur MD. Otomycosis: a clinicomycologic study. Ear Nose Throat J 2000;79(08): 606-609

4 Agarwal P, Devi LS. Otomycosis in a Rural Community Attending a Tertiary Care Hospital: Assessment of Risk Factors and Identification of Fungal and Bacterial Agents. J Clin Diagn Res 2017;11(06): DC14-DC18

5 Aneja KR, Sharma C, Joshi R. Fungal infection of the ear: a common problem in the north eastern part of Haryana. Int J Pediatr Otorhinolaryngol 2010;74(06):604-607

6 Hueso Gutiérrez P, Jiménez Alvarez S, Gil-Carcedo Sañudo E, GilCarcedo García LM, Ramos Sánchez C, Vallejo Valdezate LA. [Presumption diagnosis: otomycosis. A 451 patients study]. Acta Otorrinolaringol Esp 2005;56(05):181-186

7 Abdelazeem M, Gamea A, Mubarak H, Elzawawy N. Epidemiology, causative agents, and risk factors affecting human otomycosis infections. Turk J Med Sci 2015;45(04):820-826
8 Ozcan KM, Ozcan M, Karaarslan A, Karaarslan F. Otomycosis in Turkey: predisposing factors, aetiology and therapy. J Laryngol Otol 2003;117(01):39-42

9 Yavo W, Kassi RR, Kiki-Barro PC, et al. [Prevalence and risk factors for otomycosis treated in the hospital setting in Abidjan (Ivory Coast)]. Med Trop (Mars) 2004;64(01):39-42

10 Kaya $A D$, Kiraz N. In vitro susceptibilities of Aspergillus spp. causing otomycosis to amphotericin B, voriconazole and itraconazole. Mycoses 2007;50(06):447-450

11 Szigeti G, Sedaghati E, Mahmoudabadi AZ, et al. Species assignment and antifungal susceptibilities of black aspergilli recovered from otomycosis cases in Iran. Mycoses 2012;55(04):333-338

12 Ho HC, Hsiao SH, Lee CY, Tsai CC. Treatment of refractory Aspergillus otomycosis with voriconazole: case series and review. J Laryngol Otol 2014;128(06):547-551

13 Romsaithong S, Tomanakan K, Tangsawad W, Thanaviratananich S. Effectiveness of 3 per cent boric acid in 70 per cent alcohol versus 1 per cent clotrimazole solution in otomycosis patients: a randomised, controlled trial. J Laryngol Otol 2016;130(09):811-815

14 Meurman O, Koskensalo A, Rantakokko-Jalava K. Evaluation of Vitek 2 for identification of yeasts in the clinical laboratory. Clin Microbiol Infect 2006;12(06):591-593

15 John H, Ghannoum MA, Barbara D, et al. Method for antifungal disk diffusion susceptibility testing of yeasts; approved guideline in "Clinical and Laboratory Standards Institute"CLSI", 2nd ed" 2009; 29 (NO 17) Document M44-A2.

16 Sekhon AS, Garg AK. A 13-year (1972-1984) study of dermatophytic infections in Alberta, Canada. Mykosen 1986;29(06):255-262

17 Ullmann U, Blasius C. [A modified simple method for the detection of the different lipolytic activity of microorganisms (author's transl)]. Zentralbl Bakteriol [Orig A] 1974;229(02):264-267

18 Barati B, Okhovvat SAR, Goljanian A, Omrani MR. Otomycosis in central iran: a clinical and mycological study. Iran Red Crescent Med J 2011;13(12):873-876

19 Pradhan B, Tuladhar NR, Amatya RM. Prevalence of otomycosis in outpatient department of otolaryngology in Tribhuvan University Teaching Hospital, Kathmandu, Nepal. Ann Otol Rhinol Laryngol 2003;112(04):384-387

20 Martin TJ, Kerschner JE, Flanary VA. Fungal causes of otitis externa and tympanostomy tube otorrhea. Int J Pediatr Otorhinolaryngol 2005;69(11):1503-1508

21 Prakash SB, Leelatejaswini RM, Deekshita V. A Clinical and Microbial Study of Otomycosis: An Original Study. J Evol Med Dental Sci 2015;4(71):12376-12384

22 Barbara DA, Michael AP. Contemporary Tools for the Diagnosis and Management of Invasive Mycoses. Clin Infect Dis 2006;43 (Suppl):S15-S27

23 Satish HS, Viswanatha B, Manjuladevi M. A Clinical Study of Otomycosis. IOSR J Dental Med Sci 2013;5(02):57-62

24 Ghiacei S. Survey of Otomycosis in north-western area of Iran. Med J Mashhad Uni Med Sci 2001;43(03):85-87

25 Kurnatowski P, Filipiak A. Otomycosis: prevalence, clinical symptoms, therapeutic procedure. Mycoses 2001;44(11-12):472-479

26 Panchal P, Pethani J, Patel D, Rathod S, Shah P. Analysis of various fungal agents in clinically suspected cases of otomycosis. Indian J Basic Appl Med Res 2013;2(08):12-19

27 Fasunla J, Ibekwe T, Onakoya P. Otomycosis in western Nigeria. Mycoses 2008;51(01):67-70

28 Olszewski MA, Noverr MC, Chen GH, et al. Urease expression by Cryptococcus neoformans promotes microvascular sequestration, thereby enhancing central nervous system invasion. Am J Pathol 2004;164(05):1761-1771

29 Stehr F, Kretschmar M, Kroger C, Hube B, Schafer W. Microbial lipases as virulence factors. J Mol Catal, B Enzym 2003;22(5-6): 347-355

30 Yike I. Fungal proteases and their pathophysiological effects. Mycopathologia 2011;171(05):299-323 